\title{
MDCO-216 Does Not Induce Adverse Immunostimulation, in Contrast to Its Predecessor ETC-216
}

\author{
Joannes A. A. Reijers ${ }^{1,2}$ • D. G. Kallend ${ }^{3}$ - K. E. Malone ${ }^{4,5}$ • J. W. Jukema ${ }^{6}$ • \\ P. L. J. Wijngaard ${ }^{7} \cdot$ J. Burggraaf $^{1} \cdot$ M. Moerland ${ }^{1}$
}

Published online: 26 August 2017

(C) The Author(s) 2017. This article is an open access publication

\begin{abstract}
Purpose Aim of this study was to demonstrate that MDCO216 (human recombinant Apolipoprotein A-I Milano) does not induce adverse immunostimulation, in contrast to its predecessor, ETC-216, which was thought to contain host cell proteins (HCPs) that elicited an inflammatory reaction.

Methods Data were taken from a clinical trial in which 24 healthy volunteers (HV) and 24 patients with proven stable coronary artery disease (sCAD) received a single intravenous dose of MDCO-216, ranging 5-40 mg/kg. Additionally, whole blood from $35 \mathrm{HV}, 35 \mathrm{sCAD}$ patients and 35 patients requiring acute coronary intervention (aCAD group) was stimulated ex vivo with MDCO-216 and ETC-216.

Results No inflammatory reaction was observed in $\mathrm{HV}$ and sCAD patients following MDCO-216 treatment, judging by body temperature, white cell counts, neutrophil counts, Creactive protein, circulating cytokines (IL- 6 , TNF- $\alpha$ ), and adverse events. In the ex vivo experiment, the geometric means
\end{abstract}

Joannes A. A. Reijers

jreijers@chdr.nl

1 Centre for Human Drug Research, Zernikedreef 8, 2333CL Leiden, The Netherlands

2 Department of Rheumatology, Leiden University Medical Center, Leiden, The Netherlands

3 The Medicines Company, Zürich, Switzerland

4 Good Biomarker Sciences, Leiden, The Netherlands

5 Present address: Janssen Prevention Center, Janssen Vaccines and Prevention B.V, Leiden, The Netherlands

6 Department of Cardiology, Leiden University Medical Center, Leiden, The Netherlands

7 The Medicines Company, Parsippany, NJ, USA
(SD) of the ratio of MDCO-216 stimulated IL-6 over background levels were 0.8 (1.9), 0.7 (1.5), 1.0 (2.0) for respectively HV, sCAD, aCAD. The corresponding ETC-216 stimulated values were 15.8 (2.9), 9.5 (3.6), 3.8 (4.0). TNF- $\alpha$ results were comparable. Because many ETC-216 stimulated samples had cytokine concentrations $>$ ULOQ, ratios were categorised and marginal homogeneity of the contingency table (MDCO-216 versus ETC-216) was assessed with the Stuart-Maxwell test. $P$ values were $\leq 0.0005$ for all populations.

Conclusions MDCO-216 did not induce adverse immunostimulation in $\mathrm{HV}$ and $\mathrm{SCAD}$ patients, in contrast to ETC-216. Results from the ex vivo stimulation suggests the same holds true for $\mathrm{aCAD}$ patients.

Keywords Immunostimulation · MDCO-216 · ETC-216 · Ex vivo stimulation $\cdot$ Apolipoprotein A-I Milano

\section{Introduction}

Over the past decades high density lipoprotein (HDL) and Apolipoprotein A-I (ApoA-I) have been targeted in the pursuit of therapies that reduce the risk of cardiovascular events [1]. One of these therapies is ApoA-I Milano (ApoA- $\mathrm{I}_{\mathrm{M}}$ ), a naturally occurring mutant of ApoA-I which was found to be associated with cardioprotective effects $[2,3]$.

Because of these effects, a human recombinant ApoA- $\mathrm{I}_{\mathrm{M}}$, codenamed ETC-216, was developed by Esperion Therapeutics in the nineties. In vitro results with recombinant $\mathrm{ApoA}-\mathrm{I}_{\mathrm{M}}$ demonstrated enhanced reverse cholesterol transport, and in animal models regression of atherosclerotic plaques was observed [4].

ETC-216 induced profound lipid changes in the initial phase I study (unpublished results), resulting in a lipid profile that closely resembled carriers of the ApoA- $\mathrm{I}_{\mathrm{M}}$ mutation. However, dosedependent increases in neutrophils, paralleling decreases in 
lymphocytes were observed as well. This phenomenon was first seen in males at a dose level of $50 \mathrm{mg} / \mathrm{kg}$ (neutrophil increase $>200 \%$ ), and in females at a dose level of $15 \mathrm{mg} / \mathrm{kg}$ (increase $\sim 80 \%$ ).

After decreasing the infusion rate from $1.67 \mathrm{mg} / \mathrm{kg} / \mathrm{min}$ for males and females to $1.25 \mathrm{mg} / \mathrm{kg} / \mathrm{min}$ for males and $0.83 \mathrm{mg} /$ $\mathrm{kg} / \mathrm{min}$ for females, a dose of $100 \mathrm{mg} / \mathrm{kg}$ in males and a dose of $50 \mathrm{mg} / \mathrm{kg}$ in females was required to induce equal changes in neutrophils and lymphocytes (Fig. 1). Maximum change from baseline in WBC counts was observed at $4 \mathrm{~h}$ after the start of the infusion, returning to baseline twenty hours later.

A similar dose-dependent pattern was seen for the adverse events reported within $24 \mathrm{~h}$ of administration. Following $15 \mathrm{mg} / \mathrm{kg}$ ETC-216 in healthy females, and following $50 \mathrm{mg} / \mathrm{kg}$ ETC-216 in healthy males respectively $2 / 3$ and $1 / 3$ participants developed gastrointestinal symptoms (nausea, vomiting, diarrhoea). Lowering the infusion rate reduced the incidence of these events; however, at $100 \mathrm{mg} / \mathrm{kg} 3 / 3$ participants reported gastrointestinal symptoms. These events occurred approximately $2-4 \mathrm{~h}$ after infusion and were sometimes accompanied by systemic symptoms, such as diaphoresis and changes in body temperature.

In the subsequently executed phase II study in patients with an acute coronary syndrome (ACS) [5], it was shown that doses up to $45 \mathrm{mg} / \mathrm{kg}$ ETC-216 were associated with a significant regression of the atherosclerotic burden. Not many adverse events were reported, although in a single patient a possible hypersensitivity reaction was noted, consisting of gastrointestinal complaints, rash, chills, and diaphoresis.

Despite the overall promising results, clinical development was halted after a serious adverse reaction had occurred early during the third clinical trial in one patient. When administered intravenously within the hour after percutaneous coronary intervention (PCI), a patient developed a severe reaction during infusion, consisting of flushing, chills, hypotension, ultimately leading to multi-organ failure.

Because the available data pointed to a systemic inflammatory reaction, contamination of the infused drug product was considered. Careful evaluation of the entire manufacturing process revealed that ETC-216 contained small quantities of residual host cell proteins (HCP) that elicited an immune response (unpublished results). Importantly, these effects remained undetected during preclinical development, and became apparent only when the drug was administered to humans, even though all appropriate standards and guidelines had been followed.

A component of the HCP in the ETC-216 drug product was demonstrated to be flagellin, using an assay based on the human toll-like receptor (TLR)-5 [6]. Other impurities included an oligopeptide binding protein (OppA), a dipeptide binding protein (DppA), and maltose-binding periplasmic protein (MalE) [7].

Due to the physical characteristics of ApoA- $\mathrm{I}_{\mathrm{M}}$ reducing these impurities proved difficult and was ultimately achieved by selectively deleting the genes encoding some of the contaminating proteins and by other significant improvements to the downstream manufacturing process [7-9]. Hereafter, recombinant ApoA- $\mathrm{I}_{\mathrm{M}}$ was reintroduced as MDCO-216 by the Medicines Company and was tested in healthy volunteers and in patients with stable coronary artery disease (CAD) [10].

This article describes the results of ex vivo stimulation of whole blood samples with ETC-216 and MDCO-216 in three populations (healthy volunteers, patients with stable $\mathrm{CAD}$, and patients with acute $\mathrm{CAD}$ ). The aim was to characterise the differences in cytokine releasing potential between both drug products. To confirm that the HCPs that induced an inflammatory response were indeed successfully eliminated, the in vivo experience with MDCO-216 was compared to the ex vivo results.

\section{Methods}

\section{Populations}

Table 1 summarises the inclusion criteria of the investigated populations; these encompass both the in vivo and ex vivo exposed populations. Data on the in vivo experience with MDCO-216 came from a randomised, double-blind phase I clinical trial [10], in which 24 healthy volunteers (HV) and 24 patients with stable CAD (SCAD) received a single intravenous dose of 5-40 mg/kg MDCO-216 or placebo.

All subjects enrolled in this trial were also challenged ex vivo with both ETC-216 and MDCO-216, together with those screened for participation and meeting the criteria as listed in Table 1. All trial participants provided written informed consent.

Acute $\mathrm{CAD}(\mathrm{aCAD})$ patients were recruited from patients with an acute coronary syndrome (ACS) who presented to the department of cardiology of the Leiden University Medical Center (Leiden, The Netherlands) for a percutaneous coronary intervention (PCI). After verbal approval the blood sample for ex vivo stimulation was collected alongside the routine clinical samples. Written consent was asked at a later stage; if not provided, the blood sample was destroyed and not analysed.

Approval was obtained from independent ethics committees for all trials and related procedures prior to the start of the respective studies, in accordance with pertaining legal requirements.

\section{Ex Vivo Exposure}

Ex vivo stimulations were performed at Good Biomarker Sciences (GBS, Leiden, The Netherlands). Heparinised whole blood samples (18 mL, BD Vacutainer, Becton Dickinson, Breda, The Netherlands) were collected and incubated for $4 \mathrm{~h}$ at $37^{\circ} \mathrm{C}$ in a humidified atmosphere with $5 \% \mathrm{CO}_{2}$, before flash-freezing the supernatant for subsequent analysis. Tested 

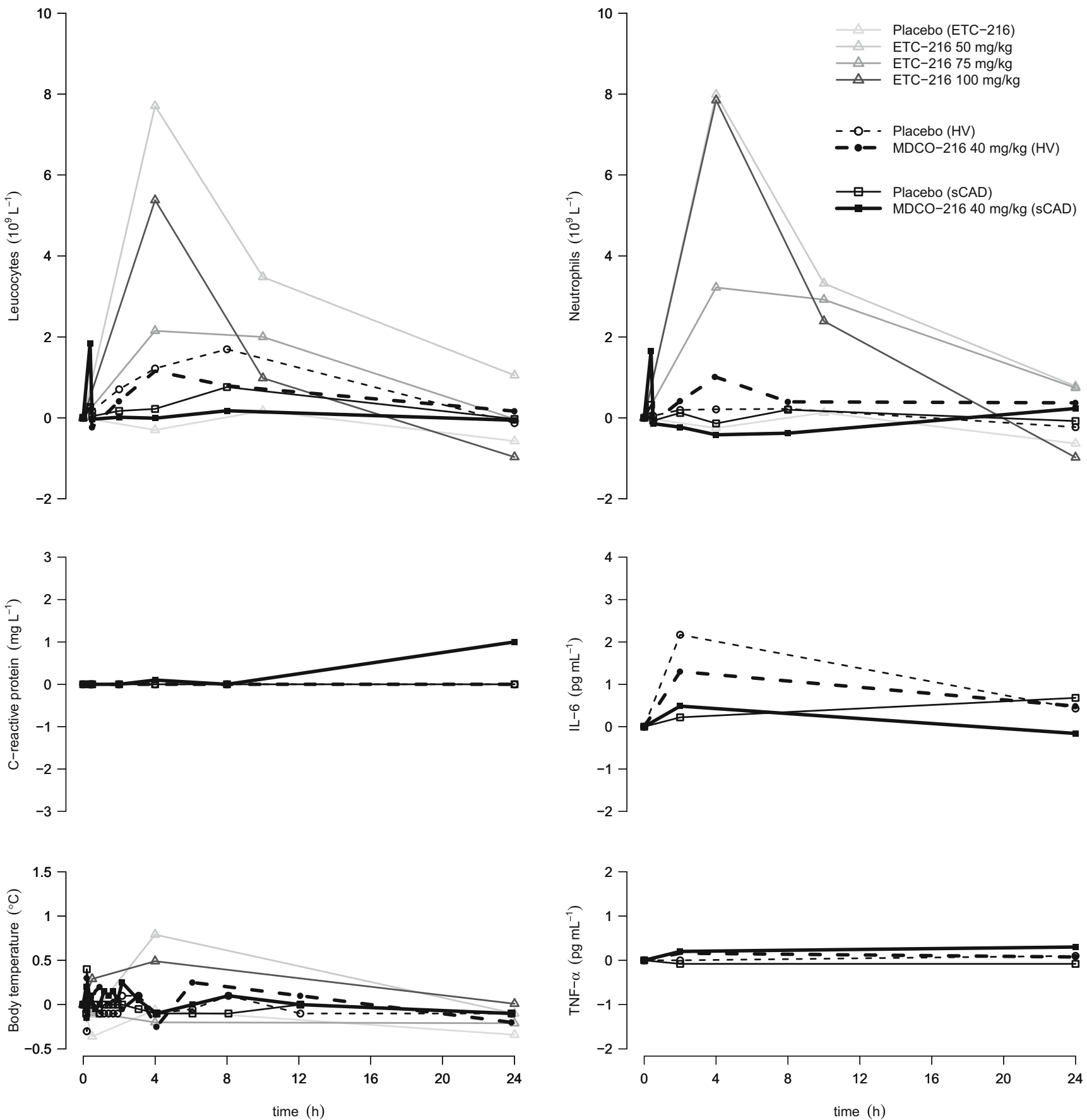

Fig. 1 In vivo results. Absolute change (median) over time in clinical markers of inflammation is displayed for placebo and the highest dose $(40 \mathrm{mg} / \mathrm{kg})$ of MDCO-216 in healthy volunteers (HV) and in patients with stable coronary artery disease (sCAD). As a reference, the median profiles over time in males in the placebo and highest dose groups from the (unpublished) phase I ETC-216 trial are projected in the background.

Of note, $75 \mathrm{mg} / \mathrm{kg}$ and $100 \mathrm{mg} / \mathrm{kg}$ of ETC-216 were administered at half the infusion rate as was $50 \mathrm{mg} / \mathrm{kg}$ of ETC-216 (see main body). Oral temperature served as body temperature in the ETC-216 phase I trial, whereas tympanic membrane temperature was used in the MDCO-216 phase I trial

conditions were $0.5 \mathrm{mg} / \mathrm{mL}$ ETC-216 (The Medicines Company, Zürich, Switzerland), $0.5 \mathrm{mg} / \mathrm{mL}$ MDCO-216 (The Medicines Company, Zürich, Switzerland), $2 \mathrm{ng} / \mathrm{mL}$ lipopolysaccharide (LPS) gel extracted from E. coli serotype O111:B4 (Sigma-Aldrich, St. Louis MO, USA), blanc (unstimulated control). The concentration of $0.5 \mathrm{mg} / \mathrm{mL}$ for

ETC-216 and MDCO-216 correlates with the maximum plasma concentration achieved following an in vivo dose of 20 $30 \mathrm{mg} / \mathrm{kg}$. LPS concentration is based on the $\mathrm{EC}_{90}$ of maximum TNF- $\alpha$ release and serves as a positive control. Conditions were made in RPMI with $25 \mathrm{mM}$ HEPES and Lglutamine (GIBCO products from Life Technologies Europe, 
Table 1 Investigated populations

\begin{tabular}{|c|c|c|c|}
\hline & HV & sCAD & $\mathrm{aCAD}$ \\
\hline \multicolumn{4}{|l|}{ Inclusion criteria } \\
\hline Age (years) & $18-55$ & $45-80$ & $\geq 18$ \\
\hline Body weight (kg) & $\leq 110$ & $\leq 110$ & - \\
\hline BMI $\left(\mathrm{kg} / \mathrm{m}^{2}\right)$ & $18-25$ & $\leq 40$ & - \\
\hline Coronary event & - & $\begin{array}{l}\text { requiring a revascularisation } \\
\text { procedure }\end{array}$ & $\begin{array}{l}\text { requiring an acute } \\
\text { revascularisation procedure }\end{array}$ \\
\hline $\begin{array}{l}\text { Latency between event } \\
\text { and exposure }\end{array}$ & - & $\geq 1$ year & $\begin{array}{l}\text { immediately prior to the } \\
\text { revascularisation procedure }\end{array}$ \\
\hline Concomitant therapy & $\begin{array}{l}\text { not allowed, except for } \\
\text { oral contraceptives }\end{array}$ & $\begin{array}{l}\text { standard of care, except for } \\
\text { HDLc-raising therapy }\end{array}$ & standard of care \\
\hline \multicolumn{4}{|l|}{ Exposure details } \\
\hline In vivo & $\begin{array}{c}\text { single dose MDCO-216 5-40 mg/kg } \\
\quad(n=16) \text { or placebo }(n=8) \text { in } 2 \mathrm{~h}\end{array}$ & $\begin{array}{l}\text { single dose MDCO-216 10-40 mg/kg } \\
(n=16) \text { or placebo }(n=8) \text { in } 2 \mathrm{~h}\end{array}$ & - \\
\hline Ex vivo & $\begin{array}{l}\text { ETC-216 } 0.5 \mathrm{mg} / \mathrm{mL} \\
\text { MDCO-216 } 0.5 \mathrm{mg} / \mathrm{mL}\end{array}$ & $\begin{array}{l}\text { ETC-216 } 0.5 \mathrm{mg} / \mathrm{mL} \\
\text { MDCO-216 } 0.5 \mathrm{mg} / \mathrm{mL}\end{array}$ & $\begin{array}{l}\text { ETC-216 } 0.5 \mathrm{mg} / \mathrm{mL} \\
\text { MDCO-216 } 0.5 \mathrm{mg} / \mathrm{mL}\end{array}$ \\
\hline
\end{tabular}

Inclusion criteria for the different populations and details of in and ex vivo exposure. $a C A D$ Patients with acute coronary artery disease (CAD); $B M I$ Body mass index; $H V$ Healthy volunteers; $s C A D$ Patients with stable coronary artery disease (CAD)

Bleiswijk, the Netherlands). Final dilution of whole blood required to achieve the tested concentrations was $10 \%$.

Ex vivo exposure of a subject to MDCO-216 always occurred prior to any in vivo exposure (HV and sCAD). Blood samples were kept at $37{ }^{\circ} \mathrm{C}$ and processed within one hour after collection, with the exception of the aCAD population, where an interval of up to $12 \mathrm{~h}$ was allowed, to increase the number of evaluable samples. Additionally, these samples from aCAD patients were kept at room temperature, since this reduces cell death and subsequent lack in responsiveness upon stimulation (data on file).

\section{Safety Assessments}

Safety assessments after in vivo exposure were performed at regular intervals during the follow up period. These consisted of vital signs, 12-lead electrocardiograms (ECGs), physical examination, registration of adverse events (AEs), and routine clinical chemistry and haematology evaluation. Safety blood samples were collected and analysed in accordance with local protocols.

\section{Cytokines}

TNF- $\alpha$ and IL- 6 were quantitated in culture supernatants and in plasma samples by Good Biomarker Sciences (GBS, Leiden, The Netherlands). For supernatants a R\&D Quantikine ELISA assay (R\&D Systems, Inc., Minneapolis, United States) was used, and for plasma samples a R\&D Quantikine HS ELISA assay. All samples from one subject were assayed in one run. LPS stimulated samples were initially measured after 20-fold and 50-fold dilution for TNF $\alpha$ and
IL-6 respectively in the manufacturer provided diluents. Other samples were initially measured undiluted. Samples were remeasured with higher dilution as needed.

TNF- $\alpha$ and IL- 6 values in the supernatants were accepted when duplicates were $<20 \% \mathrm{CV}$ for values within the calibration range: LLOQ (lower limit of quantitation) $15.6 \mathrm{pg} / \mathrm{mL}$ and $3.1 \mathrm{pg} / \mathrm{mL}$, and ULOQ (upper limit of quantitation) $1000 \mathrm{pg} / \mathrm{mL}$ and $300 \mathrm{pg} / \mathrm{mL}$, for TNF- $\alpha$ and IL- 6 respectively. TNF- $\alpha$ and IL- 6 values in the plasma samples were accepted when duplicates were $<20 \% \mathrm{CV}$ for values within the calibration range: LLOQ $0.5 \mathrm{pg} / \mathrm{mL}$ and $0.16 \mathrm{pg} / \mathrm{mL}$, and ULOQ $32 \mathrm{pg} / \mathrm{mL}$ and $10 \mathrm{pg} / \mathrm{mL}$, for TNF $\alpha$ and IL-6 respectively.

\section{Statistical Analysis}

All available data were included in the analyses unless otherwise indicated. Values $<$ LLOQ or $>$ ULOQ were replaced by respectively the LLOQ or ULOQ, as appropriate. Lognormally distributed parameters were $\ln$-transformed prior to analysis.

Individual ratios of stimulated cytokine levels over unstimulated (background) levels were calculated and compared statistically. In case of background levels $<$ LLOQ or stimulated levels $>$ ULOQ, the corresponding ratio (respectively [stimulated]/LLOQ or ULOQ/[unstimulated]) was regarded as the lower margin of the interval (calculated ratio, $\infty]$ for the purpose of categorical data analysis.

Continuous data were primarily analysed using an analysis of variance, which could include a covariance analysis to correct for confounding factors. Contrasts and effects (with 95\% confidence intervals) were calculated as relevant according to the Tukey method. If the assumption of equal variance was not 
met, multiple Welch's t-tests were performed to evaluate the validity of the statistical results.

Categorical data were analysed in a logistic regression model, which could include a covariance analysis to correct for confounding factors. For contingency tables, marginal homogeneity was tested with the Stuart-Maxwell test.

Data analysis was performed with R (v2.15.2, R Foundation for Statistical Computing, Vienna, Austria, 2012 [R Development Core Team, 2012]). Results are presented as mean (standard deviation or $95 \%$ confidence interval) for continuous data and as number (percentage) for categorical data, unless otherwise specified.

\section{Results}

\section{Ex Vivo Exposure}

In total, $35 \mathrm{HV}$ and $35 \mathrm{sCAD}$ patients, who were screened for participation in the MDCO-216 phase I clinical trial, had evaluable results following ex vivo exposure and were included in the analysis. Additionally, 38 aCAD patients signed informed consent and provided a blood sample for ex vivo testing in the prespecified period (October 2013 to May 2014), of whom 35 had evaluable results and were included in the analysis. Baseline characteristics of the different populations are presented in Table 2.
Table 3 presents the released IL- 6 upon stimulation of whole blood samples with either ETC-216 or MDCO-216 in relation to background IL-6 levels. From this table, it is seen that ETC-216 clearly elicits a cytokine response, especially when compared to MDCO-216, which seemingly inhibits spontaneous (unstimulated) cytokine release, with a geometric mean ratio of $0.7-1.0$, for respectively sCAD and aCAD. This was not caused by an interference of MDCO-216 in the measurement of IL-6, as was determined by measuring a sample with known cytokine levels with and without spiking of MDCO-216 just prior to analysis.

Because many ETC-216 stimulated samples had cytokine concentrations >ULOQ (e.g. HV: 26 [74.3\%] for IL-6 and 20 [57.1\%] for TNF- $\alpha$ ), preventing the use of an analysis of variance, the ratios of ETC-216 and MDCO-216 stimulated over background levels were categorised and marginal homogeneity of the contingency table of MDCO-216 versus ETC216 was statistically tested with the Stuart-Maxwell test. Categories were chosen as <0.2, [0.2,0.5), [0.5,1), [1,2), $[2,5), \geq 5$, based on the fact that virtually all $>$ ULOQ values resulted in a ratio greater than 5. For IL-6 the thus obtained $p$ values under the null hypothesis of marginal homogeneity were $<10^{-5},<10^{-5}$, and 0.0004 for $\mathrm{HV}$, sCAD, and $\mathrm{aCAD}$, respectively; the corresponding results for $\mathrm{TNF}-\alpha$ were $<10^{-5}$, $<10^{-4}$, and 0.0005 , indicating that ETC-216 and MDCO-216 yielded statistically significantly different cytokine responses.
Table 2 Population characteristics

\begin{tabular}{|c|c|c|c|c|c|}
\hline \multirow[b]{2}{*}{ Parameter } & \multicolumn{2}{|c|}{ exposed in vivo } & \multicolumn{2}{|c|}{ exposed ex vivo } & \multirow[b]{2}{*}{$\begin{array}{c}\mathrm{aCAD} \\
(n=35)\end{array}$} \\
\hline & $\begin{array}{c}\mathrm{HV} \\
(n=24)\end{array}$ & $\begin{array}{c}\mathrm{sCAD} \\
(n=24)\end{array}$ & $\begin{array}{c}\text { HV } \\
(n=35)\end{array}$ & $\begin{array}{c}\text { sCAD } \\
(n=35)\end{array}$ & \\
\hline Age (year) & $26.2(8.6)$ & $62.8(7.0)$ & $24.6(7.5)$ & $64.0(7.8)$ & $64.4(12.9)$ \\
\hline Height (cm) & $175(8.7)$ & $177(6.7)$ & $176(8.7)$ & $177(6.3)$ & $176(10.7)$ \\
\hline Body weight (kg) & $70.0(11.3)$ & $85.0(12.8)$ & $69.8(10.8)$ & $86.5(13.3)$ & $81.4(19.2)$ \\
\hline BMI (kg/m2) & $22.5(1.8)$ & $27.0(3.3)$ & $22.3(1.9)$ & $27.4(3.3)$ & $26.1(5.3)$ \\
\hline \multicolumn{6}{|l|}{ Gender } \\
\hline Female $(n)$ & $14(58 \%)$ & $1(4 \%)$ & $18(51 \%)$ & $1(3 \%)$ & $11(31 \%)$ \\
\hline Male $(n)$ & $10(42 \%)$ & $23(96 \%)$ & $17(49 \%)$ & $34(97 \%)$ & $24(69 \%)$ \\
\hline Revascularisation & procedure & & & & \\
\hline $\mathrm{CABG}(n)$ & & $12(50 \%)$ & & $14(40 \%)$ & \\
\hline PCI $(n)$ & & $12(50 \%)$ & & $21(60 \%)$ & $35(100 \%)$ \\
\hline \multicolumn{6}{|l|}{ Coronary involved } \\
\hline $\mathrm{Cx}(n)$ & & $6(25 \%)$ & & $10(29 \%)$ & $15(43 \%)$ \\
\hline $\operatorname{LAD}(n)$ & & $7(29 \%)$ & & $8(23 \%)$ & $19(54 \%)$ \\
\hline $\mathrm{RCA}(n)$ & & $6(25 \%)$ & & $12(34 \%)$ & $15(43 \%)$ \\
\hline Unknown $(n)$ & & $10(42 \%)$ & & $13(37 \%)$ & $12(34 \%)$ \\
\hline
\end{tabular}

Characteristics as mean (standard deviation) or number (percentage) of different populations, who were exposed in vivo to MDCO-216 or who were exposed ex vivo to both MDCO-216 and ETC-216. aCAD Patients with acute coronary artery disease (CAD); $B M I$ Body mass index; $C A B G$ Coronary artery bypass grafting; $C x$ Circumflex artery; $H V$ Healthy volunteers; $L A D$ Left anterior descending artery; $P C I$ Percutaneous coronary intervention; $R C A$ Right coronary artery; $s C A D$ Patients with stable coronary artery disease (CAD). 
Table 3 Ex vivo results

\begin{tabular}{lrrr}
\hline & $\begin{array}{l}\text { HV } \\
(n=35)\end{array}$ & \multicolumn{1}{l}{$\begin{array}{l}\text { sCAD } \\
(n=35)\end{array}$} & \multicolumn{1}{l}{$\begin{array}{l}\text { aCAD } \\
(n=35)\end{array}$} \\
\hline $\boldsymbol{I L}-\boldsymbol{6}$ & & & \\
LPS & $797.7(1.9)$ & $933.5(2.0)$ & $62.1(6.5)$ \\
ETC-216* & $15.8(2.9)$ & $9.5(3.6)$ & $3.8(4.0)$ \\
MDCO-216 & $0.8(1.9)$ & $0.7(1.5)$ & $1.0(2.0)$ \\
$\boldsymbol{T N F} \boldsymbol{- \alpha}$ & & & \\
LPS & $117.4(1.9)$ & $242.0(1.8)$ & $46.9(4.0)$ \\
ETC-216* & $9.0(2.8)$ & $6.0(3.8)$ & $3.5(4.0)$ \\
MDCO-216 & $0.8(1.8)$ & $0.7(1.9)$ & $1.0(2.0)$ \\
\hline
\end{tabular}

Geometric mean (standard deviation) of ratios of LPS, ETC-216 and MDCO-216 stimulated cytokine concentration over unstimulated (background) levels for IL- 6 and TNF- $\alpha$

*Ratios are underestimated as a result of stimulated samples being >ULOQ: for IL-6 in 26 (74.3\%) HV, 19 (54.3\%) sCAD, $16(45.7 \%)$ $\mathrm{aCAD}$; and for TNF- $\alpha$ in $20(57.1 \%) \mathrm{HV}, 24(68.6 \%) \mathrm{sCAD}, 6(17.1 \%)$

$a C A D$ Patients with acute coronary artery disease (CAD); $H V$ Healthy volunteers; $L P S$ Lipopolysaccharide; $s C A D$ Patients with stable coronary artery disease (CAD); ULOQ Upper limit of quantitation

When comparing the different populations, ETC-216 generally induced lower IL- 6 release in the CAD patients than in healthy volunteers. Lower ratios in the $\mathrm{CAD}$ populations were also obtained for the MDCO-216 stimulated samples, but LPS exposure resulted in a lower ratio in the aCAD population only. These differences could not be related to age, weight, BMI, blood pressure, (differential) leucocyte count, the severity of the CAD based on total obstruction, the coronary involved, or the type of revascularisation procedure.

The ex vivo results in the aCAD population did not substantially differ from those obtained in the sCAD population. However, some acute $\mathrm{CAD}$ patients had considerably higher background (unstimulated) IL-6 levels, up to $2664 \mathrm{pg} / \mathrm{mL}$ (median $37.3 \mathrm{pg} / \mathrm{mL}$ ), compared to a maximum of $84.4 \mathrm{pg}$ / $\mathrm{mL}$ (median $14.1 \mathrm{pg} / \mathrm{mL}$ ) in $\mathrm{SCAD}$. A relationship could not be detected between background levels and demographics or clinical parameters, such as severity of the coronary syndrome based on total coronary obstruction as estimated during acute angiography.

Bioanalytical causes for this phenomenon were not found, neither could the high background levels be related to the interval between sample collection and processing. Albeit true that a time dependent decrease in cytokine response was observed, a prolonged interval was not associated with higher background levels, and judging from the ratios, the overall effects of ETC-216, MDCO-216, and LPS in these samples were consistent with the results obtained from samples that were processed immediately after collection (data not shown).

Statistical significance was reached for the population differences in MDCO-216 and LPS stimulated results, based on an analysis of variance of the $\ln$-transformed ratios over background (unstimulated) cytokine levels, which included sex as covariate. For LPS, the difference in TNF- $\alpha$ ratios between the SCAD and HV population was $206 \%$ (95\% confidence interval $[\mathrm{CI}]: 120-355, p=0.0057)$, between $\mathrm{aCAD}$ and HV 40\% (24-68, $p=0.0002)$, and between $\mathrm{aCAD}$ and SCAD $19 \%\left(11-33, p<10^{-9}\right)$. For MDCO-216 only the difference between $\mathrm{SCAD}$ and $\mathrm{ACAD}$ populations was statistically significant (IL-6: ratio 69\% [95\%-CI: 50-95], $p=0.0170$; TNF- $\alpha$ : ratio 67\% [48-94], $p=0.0169$ ). Other covariates were not found to have a statistically significant effect, nor improved the model fit.

Population differences were difficult to test statistically for the ETC-216 stimulated condition and IL-6 results following LPS stimulation, due to many stimulated cytokine levels being $>$ ULOQ. Analysing a reduced dataset which only included values $<\mathrm{ULOQ}$ resulted in underpowered comparisons. Attempts to fit a multinomial regression model after categorising the data failed for the same reason.

\section{In Vivo Exposure}

Table 2 lists the baseline characteristics of the populations exposed to MDCO-216 in vivo. The most commonly used medication by stable CAD patients was an antithrombotic agent (96\%), mainly acetylsalicylic acid (83\%). Statins were used by $92 \%, \beta$-blockers by $58 \%$, and ACE-inhibitors by $38 \%$ of the patients.

In the HV population exposed to MDCO-216, two subjects complained of abdominal pain or distension, one (50\%) in the $10 \mathrm{mg} / \mathrm{kg}$ group and one (25\%) in the $20 \mathrm{mg} / \mathrm{kg}$ group, which started $9 \mathrm{~h}$ after administration. Stable CAD patients receiving MDCO-216, reported nausea once (4 h post dose, $20 \mathrm{mg} / \mathrm{kg}$ group) and diarrhoea once (13 h post dose, $40 \mathrm{mg} / \mathrm{kg}$ ). The latter case was a patient who had undergone a cholecystectomy and since then regularly developed diarrhoea after ingesting high-fat meals.

No inflammatory reaction was observed in $\mathrm{HV}$ and SCAD patients, judging by body temperature, white cell counts, neutrophil counts, C-reactive protein, and circulating cytokines (Fig. 1).

\section{Discussion}

Recombinant proteins represent a powerful class of drugs that is employed to supplement absent or insufficient quantities of essential enzymes, hormones, and coagulation factors. Additionally, peptides can be designed to specifically interact with cells or receptors and thus interfere in the pathophysiology of certain diseases [11-13].

However, since these proteins or peptides are invariably expressed in allogeneic, often non-human, cell systems foreign material is released into the medium together with the 
protein of interest. Countless impurities can trigger the immune system; especially bacterial based platforms, such as those using Escherichia coli, are notorious suppliers of immunostimulatory impurities like endotoxin (lipopolysaccharide or LPS) [14]. Also the remaining proteins in a pharmaceutical, collectively referred to as host cell proteins (HCP), can potentially elicit an inflammatory reaction [15].

ETC-216, expressed in E. coli, was approved for intravenous administration to humans in accordance with all pertaining regulatory guidelines. Specifically, the limulus amebocyte lysate (LAL) test was negative, HCP levels were $\leq 10 \mathrm{ppm}$, and each dose contained $<10 \mathrm{ng}$ of residual DNA.

Nevertheless, administration of ETC-216 to healthy volunteers induced dose-dependent neutrophilic leucocytosis, increases in body temperature, and gastrointestinal side effects. In CAD patients, hypersensitivity-like reactions were observed as well as gastrointestinal side effects. In retrospect, these findings are easily recognised as signs and symptoms of an inflammatory response caused by the HCP impurities.

After several modifications were made to the manufacturing process to reduce the HCP levels, the recombinant ApoA$\mathrm{I}_{\mathrm{M}}$ was reintroduced as MDCO-216. Because it was deemed unethical to expose a human population to a product with a known immunostimulatory propensity (ETC-216), an ex vivo whole blood incubation assay was applied to compare differences in cytokine response to MDCO-216 and ETC-216.

Results demonstrated that ETC-216 clearly induced cytokine release, in contrast to MDCO-216. In HV and SCAD patients, MDCO-216 even slightly inhibited (spontaneous) release. This difference was statistically significant for all populations, with $p$-values $\leq 0.0005$. The observed inhibition of approximately $30 \%$ by MDCO- 216 is in accordance with previous studies that have reported that HDL or HDL-like particles display many anti-inflammatory properties [16].

The absence of an inflammatory reaction was confirmed in a clinical trial with MDCO-216. No increases in neutrophils were observed following MDCO-216 infusion in HV and SCAD patients. Also, the more sensitive biomarkers (CRP and circulating cytokines) did not suggest immune stimulation by MDCO-216. Additionally, the observed gastrointestinal side effects did not display a dose-relationship as was seen for ETC-216, although it should be noted that MDCO-216 was infused at a lower rate compared to ETC-216.

An interesting question to be asked is whether an ex vivo incubation assay can be implemented to detect adverse immune stimulation. Certainly, a whole blood stimulation test can detect a myriad of pyrogenic substances, such as LPS, porins, lipoteichoic acid (LTA) and peptidoglycan [17-22]. Nonetheless, many uncertainties still surround the interpretation of its result [23]. Our results revealed differences in reactivity between the three tested populations, not only with regard to the HCP impurities in ETC-216, but also to LPS, which highlights some of the uncertainties.
For example, LPS stimulation resulted in higher cytokine responses in SCAD patients compared to HV, and ETC-216 induced lower levels in SCAD patients compared to HV. After correction for the differences in monocyte count, the statistically significant differences remained. Other factors, such as age, BMI, and blood pressure could not explain any of the found effects.

Comorbidities may have influenced the response, as - for example - hypertension was previously found by Dörffel et al. [24] to increase TNF- $\alpha$ and IL- $1 \beta$ secretion from peripheral blood monocytes after in vitro LPS stimulation by $>50 \%$, although these patients were untreated. The antihypertensives losartan, captopril, and amlodipine dose-dependently reduced IL- $1 \beta$ release induced by LPS, but not below LPS stimulated levels in normotensive subjects [25].

Other cardiovascular medications are also known to influence the (innate) immune response. For example, certain calcium channel blockers were observed to interfere with both flagellin and LPS signalling [26, 27]. Statins and aspirin demonstrate similar anti-inflammatory properties [28-30]. Interestingly however, whereas many cardiovascular drugs inhibit TLR-4 mediated responses, with $\beta$-blockers being a notable exception [31,32], ex vivo LPS stimulation induced higher cytokine levels in SCAD patients than in HV. Although effects of certain cardiovascular medications and conditions on toll-like receptor (TLR) signalling have not been examined as extensively for TLR-5 (flagellin) as for TLR-4 (LPS), our results suggest that the response to flagellin and other HCP impurities can be modified by these factors as well.

Notwithstanding the aforementioned effects, compared to stable CAD patients, acute CAD patients displayed higher background cytokine levels, as well as an overall diminished responsiveness to both LPS and ETC-216. Severity of the coronary disease, based on total obstruction, or the coronary involved was not related to background cytokine levels, or any of the observed effects after ex vivo stimulation with LPS, ETC-216 or MDCO-216.

ACS is associated with elevated plasma levels of proinflammatory cytokines, chemokines, and leucocytes, which are governed at least partly by TLR-4 stimulation [33, 34]. Conversely, stress hormones such as catecholamines and hydrocortisone, that have a general immune-inhibiting mode of action, are increased in parallel [35-37]. This combination might explain both the high background cytokine levels and the reduced response to ETC-216 observed in the aCAD patients. TLR-4 mediated cytokine release in ACS can also account for the observation that a subsequent (experimental) LPS challenge did only modestly increase IL- 6 and TNF- $\alpha$ concentrations ex vivo.

It should be stressed, however, that although (the consequences of) an inflammatory response can be influenced by external factors, a reduced response is not synonymous with an improved outcome, especially in critically ill patients. This 
warrants a cautious approach when exposing (vulnerable) humans to an experimental biologic. Furthermore, it underlines the current limitations of an ex vivo stimulation test in reliably predicting inflammatory reactions upon in vivo administration in the target population, although it can be used to highlight differences between two pharmacological products within a population.

Concluding, MDCO-216 does not elicit an acute immune response in healthy volunteers nor in patients with stable coronary artery disease, in contrast to what was previously observed with ETC-216. Results from an ex vivo stimulation with both products suggests the same holds true for patients with an acute coronary syndrome.

\section{Compliance with Ethical Standards}

Funding This study was sponsored by The Medicines Company, Parsippany, NJ, USA.

Conflict of Interest D.G.K. and P.L.J.W. are employees of The Medicines Company and receive share options. J.W.J. received grants and fees from The Medicines Company both outside and during the conduct of this study.

Ethical Approval All procedures performed in studies involving human participants were in accordance with the ethical standards of the institutional and/or national research committee and with the 1964 Helsinki declaration and its later amendments or comparable ethical standards.

Informed Consent Informed consent was obtained from all individual participants included in the study.

Open Access This article is distributed under the terms of the Creative Commons Attribution 4.0 International License (http:// creativecommons.org/licenses/by/4.0/), which permits unrestricted use, distribution, and reproduction in any medium, provided you give appropriate credit to the original author(s) and the source, provide a link to the Creative Commons license, and indicate if changes were made.

\section{References}

1. Boekholdt SM, Arsenault BJ, Hovingh GK, Mora S, Pedersen TR, Larosa JC, et al. Levels and changes of HDL cholesterol and apolipoprotein A-I in relation to risk of cardiovascular events among statin-treated patients: a meta-analysis. Circulation. 2013;128: 1504-12.

2. Franceschini G, Sirtori CR, Capurso A, Weisgraber KH, Mahley RW. A-IMilano apoprotein. Decreased high density lipoprotein cholesterol levels with significant lipoprotein modifications and without clinical atherosclerosis in an Italian family. J Clin Invest. 1980;66:892-900.

3. Franceschini G, Sirtori CR, Bosisio E, Gualandri V, Orsini GB, Mogavero AM, et al. Relationship of the phenotypic expression of the A-IMilano apoprotein with plasma lipid and lipoprotein patterns. Atherosclerosis. 1985;58:159-74.

4. Nicholls SJ, Uno K, Kataoka Y, Nissen SE. ETC-216 for coronary artery disease. Expert Opin Biol Ther. 2011;11:387-94.
5. Nissen SE, Tsunoda T, Tuzcu EM, Schoenhagen P, Cooper CJ, Yasin M, et al. Effect of recombinant ApoA-I Milano on coronary atherosclerosis in patients with acute coronary syndromes: a randomized controlled trial. JAMA. 2003;290:2292-300.

6. Huang L-Y, Dumontelle JL, Zolodz M, Deora A, Mozier NM, Golding B. Use of toll-like receptor assays to detect and identify microbial contaminants in biological products. J Clin Microbiol. 2009; 47:3427-34.

7. Caparon MH, Rust KJ, Hunter AK, McLaughlin JK, Thomas KE, Herberg JT, et al. Integrated solution to purification challenges in the manufacture of a soluble recombinant protein in $\mathrm{E}$ coli. Biotechnol Bioeng. 2010;105:239-49.

8. Hunter AK, Suda EJ, Herberg JT, Thomas KE, Shell RE, Gustafson $\mathrm{ME}$, et al. Separation of recombinant apolipoprotein A-IMilano modified forms and aggregates in an industrial ion-exchange chromatography unit operation. J Chromatogr A. 2008;1204:42-7.

9. Hunter AK, Wang X, Suda EJ, Herberg JT, Shell RE, Thomas KE, et al. Separation of product associating E. coli host cell proteins OppA and DppA from recombinant apolipoprotein A-I milano in an industrial HIC unit operation. Biotechnol Prog. 2009;25:446-53.

10. Kallend DG, Reijers JAA, Bellibas SE, Bobillier A, Kempen H, Burggraaf J, et al. A single infusion of MDCO-216 (ApoA-1 Milano/POPC) increases ABCA1-mediated cholesterol efflux and pre-beta $1 \mathrm{HDL}$ in healthy volunteers and patients with stable coronary artery disease. Eur Hear J Cardiovasc Pharmacother. 2016;2: 23-9.

11. Buckel P. Recombinant proteins for therapy. Trends Pharmacol Sci. 1996;17:450-6.

12. Walsh G. Biopharmaceutical benchmarks 2014. Nat Biotechnol. 2014;32:992-1000.

13. Sanchez-Garcia L, Martín L, Mangues R, Ferrer-Miralles N, Vázquez E, Villaverde A. Recombinant pharmaceuticals from microbial cells: a 2015 update. Microb Cell Fact BioMed Central. 2016:15-33.

14. Terpe K. Overview of bacterial expression systems for heterologous protein production: from molecular and biochemical fundamentals to commercial systems. Appl Microbiol Biotechnol. 2006;72:21122.

15. Wang X, Hunter AK, Mozier NM. Host cell proteins in biologics development: identification, quantitation and risk assessment. Biotechnol Bioeng. 2009;103:446-58.

16. Vuilleumier N, Dayer JM, von Eckardstein A, Roux-Lombard P. Pro- or anti-inflammatory role of apolipoprotein A-1 in highdensity lipoproteins? Swiss Med Wkly. 2013;143:1-12.

17. Cusumano V, Tufano MA, Mancuso G, Carbone M, Rossano F, Fera MT, et al. Porins of Pseudomonas Aeruginosa induce release of tumor necrosis factor alpha and interleukin- 6 by human leukocytes. Infect Immun. 1997;65:1683-7.

18. Nakagawa Y, Maeda H, Murai T. Evaluation of the in vitro pyrogen test system based on proinflammatory cytokine release from human monocytes: comparison with a human whole blood culture test system and with the rabbit pyrogen test. Clin Diagn Lab Immunol. 2002;9:588-97.

19. Hermann C, von Aulock S, Graf K, Hartung T. A model of human whole blood lymphokine release for in vitro and ex vivo use. $\mathrm{J}$ Immunol Methods. 2003;275:69-79.

20. Popa C, Netea MG, Barrera P, Radstake TRDS, van Riel PL, Kullberg B-J, et al. Cytokine production of stimulated whole blood cultures in rheumatoid arthritis patients receiving short-term infliximab therapy. Cytokine. 2005;30:72-7.

21. Draing C, Pfitzenmaier M, Zummo S, Mancuso G, Geyer A, Hartung T, et al. Comparison of lipoteichoic acid from different serotypes of Streptococcus Pneumoniae. J Biol Chem. 2006;281: 33849-59.

22. Meron-Sudai S, Matityahou A, Keisari Y, Cox KH, Hasty DL, Ofek I. Lipoteichoic acid synergizes with glycosphingolipids to potently 
stimulate secretion of interleukin-6 from human blood cells. Clin Vaccine Immunol. 2008;15:1309-15.

23. Vidal J-M, Kawabata TT, Thorpe R, Silva-Lima B, Cederbrant K, Poole $\mathrm{S}$, et al. In vitro cytokine release assays for predicting cytokine release syndrome: the current state-of-the-science. Report of a European medicines agency workshop. Cytokine. 2010;51:213-5.

24. Dörffel Y, Latsch C, Stuhlmuller B, Schreiber S, Scholze S, Burmester GR, et al. Preactivated peripheral blood monocytes in patients with essential hypertension. Hypertension. 1999;34:113-7.

25. Nemati F, Rahbar-Roshandel N, Hosseini F, Mahmoudian M, Shafiei M. Anti-inflammatory effects of anti-hypertensive agents: influence on interleukin- $1 \beta$ secretion by peripheral blood polymorphonuclear leukocytes from patients with essential hypertension. Clin Exp Hypertens. 2011;33:66-76.

26. Li G, Qi XP, Wu XY, Liu FK, Xu Z, Chen C, et al. Verapamil modulates LPS-induced cytokine production via inhibition of NFkappa B activation in the liver. Inflamm Res. 2006;55:108-13.

27. Chen Y-L, Chen Y-S, Lin H-H, Chan C-W, Chen S-C, Chen C-H. Immunostimulatory flagellin from Burkholderia pseudomallei effects on an increase in the intracellular calcium concentration and up-regulation of TNF-alpha by mononuclear cells. Microbiol Immunol. 2007;51:81-6.

28. Sadowitz B, Maier KG, Gahtan V. Basic science review: statin therapy-part I: the pleiotropic effects of statins in cardiovascular disease. Vasc Endovasc Surg. 2010;44:241-51.

29. Akinosoglou K, Alexopoulos D. Use of antiplatelet agents in sepsis: a glimpse into the future. Thromb Res Elsevier Ltd. 2014;133: $131-8$.
30. Ruggieri A, Gambardella L, Maselli A, Vona R, Anticoli S, Panusa A, et al. Statin-induced impairment of monocyte migration is gender-related. J Cell Physiol. 2014;229:1990-8.

31. Yurinskaya MM, Vinokurov MG, Grazhdankin EB, Grachev SV. The effect of propranolol on LPS-induced activation of human neutrophils. Dokl Biochem Biophys. 2010;435:330-3.

32. Stanojevic S, Dimitrijevic M, Kustrimovic N, Mitic K, Vujic V, Leposavic G. Adrenal hormone deprivation affects macrophage catecholamine metabolism and beta2-adrenoceptor density, but not propranolol stimulation of tumour necrosis factor-alpha production. Exp Physiol. 2013;98:665-678.

33. Fang L, Moore X-L, Dart AM, Wang L-M. Systemic inflammatory response following acute myocardial infarction. J Geriatr Cardiol. 2015;12:305-12.

34. Liebetrau C, Hoffmann J, Dorr O, Gaede L, Blumenstein J, Biermann $\mathrm{H}$, et al. Release kinetics of inflammatory biomarkers in a clinical model of acute myocardial infarction. Circ Res. 2015;116:867-75.

35. Logan RW, Murdoch WR. Blood-levels of hydrocortisone, transaminases, and cholesterol after myocardial infarction. Lancet (London, England). 1966;2:521-4.

36. Hansen B, Beck-Nielsen J, Juul J, Nielsen BL, Nielsen FU. Plasmahydrocortisone values in heart disease. Results after acute myocardial infarction (with and without cardiogenic shock) and in patients with congestive heart failure. Acta Med Scand. 1969;186:411-6.

37. Sigurdsson A, Held P, Swedberg K. Short- and long-term neurohormonal activation following acute myocardial infarction. Am Heart J. 1993;126:1068-76. 